\title{
BRCA1 AND MICRORNAS 7, 10B, 205AB, 218A EXPRESSION AS PROGNOSTIC MARKERS IN PRIMARY BREAST CANCERS - A RETROSPECTIVE COHORT STUDY
}

Cesar A. S. T. Vilanova-Costa $a^{1,2}$, Jéssica E. P. Ramos³, Juliana F. Paes ${ }^{4}$, Daniel R. Bastos ${ }^{1}$, Nathália A. Nogueira ${ }^{1,4}$, Silvia H. Rabelo-Santos ${ }^{6}$, Raphael B. Parmigiani , Vera A. Saddi ${ }^{1,3,4,5}$

'Laboratório de Genética e Biodiversidade, Programa de Pós-graduação em Ciências Ambientais e Saúde, Pontifícia Universidade Católica de Goiás - Goiânia (GO), Brazil.

Laboratório de Biologia Tumoral, Hospital Araújo Jorge, Associação de Combate ao Câncer em Goiás - Goiânia (GO), Brazil. ${ }^{3}$ Escola de Ciências Médicas, Farmacêuticas e Biomédicas, Pontifícia Universidade Católica de Goiás - Goiânia (GO), Brazil. 4Programa de Pós-graduação em Ciências da Saúde, Universidade Federal de Goiás - Goiânia (GO), Brazil.

'Laboratório de Oncogenética e Radiobiologia, Instituto de Ensino e Pesquisa, Associação de Combate ao Câncer em Goiás - Goiânia (GO), Brazil.

${ }^{6}$ Instituto de Patologia Tropical, Universidade Federal de Goiás - Goiânia (GO), Brazil.

${ }^{7}$ Idengene Medicina Diagnóstica - São Paulo (SP), Brazil.

Micro-RNAs (miRs) are post-transcriptional regulators of gene expression involved in several important biological processes. BRCA1 is a tumor suppressor gene and BRCA1-silent breast cancers (BC) tend to be more aggressive. Since BRCA1 may be regulated at post-transcriptional level by miRNAs, the purpose of this study was to evaluate the prognostic value of human miR-7, miR-10b, miR-205ab and miR-218b and BRCA1 expression levels in BC. A set of 36 triple-negative (TN) and 56 nontriple-negative (NTN) breast tumors was analyzed. Total miRNA was extracted from formalin-fixed paraffin-embedded (FFPE) BCs collected from the Pathology Department of Araújo Jorge Hospital-ACCG (Goiânia, Goiás, Brazil). MiRs expression was quantified by Quantitative Real-Time PCR (qRT-PCR) and BRCA1 expression was evaluated by immunohistochemistry (IHC). The present study was approved by the institutional Ethics Committee of Araújo Jorge Hospital (Report $\left.n^{\circ} 948.930,2015\right)$. The relative expression levels of miRs and clinic pathological features of breast cancers were compared. Overall survival in 60 months was $72.8 \%$, and it was influenced by TNBC phenotype ( $p=0.044)$, tumor size $(\mathrm{p}=0.007)$, lymph node involvement ( $\mathrm{p}=0.038)$, distant metastasis $(\mathrm{p}=0.0008)$, BRCA1 negative expression (0.039), miR-7 ( $\mathrm{p}=0.026)$ and miR-10b ( $\mathrm{p}=0.011)$ overexpression. MicroRNA hsa-miR-7 overexpression was associated with larger tumors $(>2 \mathrm{~cm})(\mathrm{p}=0.041)$, higher histological grade $(\mathrm{p}=0.028)$, TN phenotype $(\mathrm{p}=0.012)$, BRCA1negative expression $(\mathrm{p}=0.047)$ and worse survival $(\mathrm{p}=0.026)$. Overexpression of hsa-miR-10b was associated with larger tumors $(\mathrm{p}=0.047)$, lymph node $(\mathrm{p}=0.032)$ and distant metastases $(0.019)$, higher histological grade $(\mathrm{p}=0.009)$, TN phenotype ( $\mathrm{p}=0.027)$, BRCA1-negative expression. $(\mathrm{p}=0.006)$ and worse survival $(\mathrm{p}=0.011)$. Meanwhile, underexpression of hsa-miR-205ab was associated with larger tumors ( $\mathrm{p}=0.027)$, lymph node $(\mathrm{p}=0.046)$ and distant metastases $(\mathrm{p}=0.014)$, BRCA1-negative expression ( $\mathrm{p}=0.027)$, TN phenotype $(\mathrm{p}=0.038)$ and worse survival $(\mathrm{p}=0.024)$. While, hsa-miR-218a underexpression was associated with a larger tumor size $(\mathrm{p}=0.032)$, lymph node $(\mathrm{p}=0.011)$ and distant metastases $(\mathrm{p}=0.022)$, TN phenotype ( $p=0.019)$, negative expression of BRCA1 $(p=0.039)$ and worse survival $(p=0.003)$. Our results show that BRCA1 protein expression assessment, miR-7 and miR-10b overexpression and miR-205ab and miR-218b underexpression could be useful in evaluating BCs prognosis, especially for patients with triple negative tumors. 